\title{
ASSOCIATION BETWEEN PSYCHOSOCIAL CHARACTERISTICS OF WORK AND PRESENTEEISM: A CROSS-SECTIONAL STUDY
}

\author{
HEIDI JANSSENS ${ }^{1}$, ELS CLAYS ${ }^{1}$, BART DE CLERCQ ${ }^{1}$, DIRK DE BACQUER ${ }^{1}$, ANNALISA CASINI², \\ FRANCE KITTEL ${ }^{2}$, and LUTGART BRAECKMAN ${ }^{1}$
}

${ }^{1}$ Ghent University, Ghent, Belgium

Department of Public Health, University Hospital Block K3(4)

${ }^{2}$ Free University of Brussels, Brussels, Belgium

Research Centre Social Approaches of Health, School of Public Health

\begin{abstract}
Objectives: This study aimed at investigating cross-sectional relationships between psychosocial characteristics of work and presenteeism in a sample of Belgian middle-aged workers. Material and Methods: Data were collected from 1372 male and 1611 female workers in the Belstress III study. Psychosocial characteristics assessed by the use of self-administered questionnaires were: job demands, job control, social support, efforts, rewards, bullying, home-to-work conflict and workto-home conflict. Presenteeism was measured using a single item question, and it was defined as going to work despite illness at least 2 times in the preceding year. Logistic regression models were used to investigate the relationship between psychosocial characteristics and presenteeism, while adjusting for several socio-demographic, health-related variables and neuroticism. An additional analysis in a subgroup of workers with good self-rated health and low neuroticism was conducted. Results: The prevalence of presenteeism was 50.6\%. Overall results, adjusted for major confounders, revealed that high job demands, high efforts, low support and low rewards were associated with presenteeism. Furthermore, a significant association could be observed for both bullying and work-to-home conflict in relation to presenteeism. The subgroup analysis on a selection of workers with good self-rated health and low neuroticism generally confirmed these results. Conclusions: Both job content related factors as well as work contextual psychosocial factors were significantly related to presenteeism. These results suggest that presenteeism is not purely driven by the health status of a worker, but that psychosocial work characteristics also play a role.
\end{abstract}

Key words:

Job stress, Sickness presence, Psychosocial risk factors, Bullying, Work-family conflict, Workload

\section{INTRODUCTION}

Presenteeism is employees' behavior that during the last decades has received an increasing interest from several investigators in the field of workplace health, stress and productivity. Following the European behavioral approach, presenteeism refers to a phenomenon when a worker turns up at work despite feeling so ill that he or she judges that sick leave would have been appropriate [1]. Another approach, followed by researchers mainly from the US, generally focuses on the productivity loss as a consequence of this specific behavior [2]. Prevalence figures of presenteeism are not consistent and vary between studies, ranging $27-88 \%$,

The Belstress III study was funded by the Belgian Federal Service Employment, Labor and Social Dialogue, and by the European Social Fund. This funding source has no role in the study design, collection, analysis and interpretation of the data, writing of the report and in the decision to submit this paper for publication. Received: January 25, 2015. Accepted: May 29, 2015.

Corresponding author: H. Janssens, Ghent University, University Hospital Block K3(4), De Pintelaan 185, B-9000 Ghent, Belgium (e-mail: heidi.janssens@ugent.be). 
depending on the type of an applied questionnaire [3-5]. Overall, presenteeism can be considered as a rather widespread behavior among employees.

Presenteeism has been demonstrated to harm the health of an employee, which is - according to the allostatic load hypothesis [6] - probably caused by accumulated tiredness resulting from inadequate recuperation from illness [7]. Prospective studies have found that sickness presenteeism was an independent risk factor for future poor general health and physical complaints [8,9] but also for mental health problems, exhaustion, and burnout [10-14]. Some authors have additionally observed a prospective relationship between presenteeism and sick leave, indicating that attending work while being ill may be a risk factor for future absenteeism [15,16]. Besides negative consequences for an individual worker, also the economic impact of presenteeism has been a subject of investigation. Generally, presenteeism involves a worker not being able to work at full capacity and is consequently associated with productivity loss for an employer. A number of researchers have made a calculation of costs related to presenteeism and some have suggested that these costs even exceed those associated with sickness absence $[17,18]$. Since presenteeism includes negative consequences for both - an individual employee and an employer, it is important to define clues for the direction of preventive measures. Besides the health status of an employee, which apparently has been demonstrated to be an important determinant of this behavior [3,19], several authors have focused on identifying work-related psychosocial factors associated with high rates of presenteeism.

Earlier research has mainly focused on job content related risk factors, such as job demands [20], time pressure [5,21] and low replaceability [1,3,5,22], which were all demonstrated to be positively correlated with presenteeism. Also job insecurity [23] and mismatch between desired and actual working hours [22] were the risk factors for presenteeism. However, the relationship between presenteeism and job control is less clear. Generally, high control is considered a risk factor for presenteeism, since control may reflect the possibility to adjust the work to the reduced capacities of a sick worker [24]. However, Aronsson and Gustafsson have observed that low control over work pace was also associated with presenteeism [5].

In previous research work contextual factors with regard to presenteeism have been addressed to a lesser extent. Supervisor support is a contextual factor that has been examined in earlier studies, but the precise nature of its relationship with presenteeism remains unclear. Both high and lack of social support have been proposed as risk factors for presenteeism [25].

To the best of our knowledge, the association between presenteeism and bullying, which can be seen as a more extreme negative psychosocial contextual work situation, has not been thoroughly investigated yet. Former research has revealed that bullying was a risk factor for sickness absence [26-28], and bullying was also demonstrated as a risk for several health problems [29-31]. In contrast, results about the relationship between this psychosocial factor and presenteeism are restricted to a short report from the 5th European Survey on Working Conditions, which has revealed a positive association between bullying and presenteeism [32].

Another emerging psychosocial factor, which has not yet been intensively studied in relation with presenteeism, is work-family conflict. Theoretically, 2 directions in workfamily conflict are recognized: work-to-home conflict or the extent to which work demands negatively affect the family role and home-to-work conflict or the extent to which family responsibilities are hampering the work role. Although earlier studies have demonstrated that both work-to-home and home-to-work conflicts caused distress and, therefore, were related to health problems, the relationship with attendance behavior is less investigated. Home-to-work conflict has been revealed as a risk factor for sickness absence [33], while Johns [34] has demonstrated, in a small study sample, that only work-to-home conflict predicted presenteeism. 
This study aimed at contributing to the existing literature on psychosocial determinants of presenteeism, by investigating the cross-sectional relationship between several psychosocial factors and presenteeism in a group of Belgian workers, adjusting for several health-related and personality variables. In addition to more commonly investigated factors based on the widespread Job DemandControl-Support (JDCS) [35] and Effort-Reward Imbalance (ERI) [36] models, we also investigated the relationship with more emerging work contextual risk factors relating to bullying and work-family conflict.

\section{MATERIAL AND METHODS}

\section{Study population}

The relationship between psychosocial factors and presenteeism was examined within the Belstress III study [33]. This study was conducted in 7 companies or public administrations across Belgium in 2004. All workers aged 30-55 years received a personal letter inviting them to volunteer. A total of 2983 workers joined the study, resulting in a response rate of $30.4 \%$. Analysis of the non-respondents revealed no important differences regarding age and gender [37].

The study population consisted of 1372 men (46\%) and 1611 women (54\%) who were employed within 3 (semi-)public administrations (53\% of the sample), 3 companies from the service sector (healthcare or social work) (39\% of the sample) and 1 manufacturing company ( $8 \%$ of the sample). The majority of the participants $(72 \%)$ worked full-time.

The Belstress III study was approved by the ethics committees of the University of Ghent and the Faculty of Medicine of the Free University of Brussels.

\section{Data collection}

Data were collected using a self-administered questionnaire, including standardized measures for individual and socio-demographic variables, health behaviors and characteristics of the psychosocial work environment.

\section{Dependent variable}

The measure of presenteeism was based on a single question assessing how frequent employees came to work despite illness during the last year. Response categories were: "never," "1 time," "2 to 5 times," "more than 5 times." Persons who reported that they came to work despite being ill 2-5 times or more during the past year were considered as demonstrating presenteeism, following earlier research in this field [3,5,21].

\section{Independent variables}

Work-related psychosocial factors were assessed based on the JDCS- [35] and the ERI-model [36], using 4-point Likert items.

Job demands consisted of 5 items, which related to mental work load, organization restrictions on task completion and conflicting demands. An example item is: "My job requires that I work very fast." The Cronbach's $\alpha$ of this scale was 0.69 . Job control was composed of the sum score of 9 items and consisted of 2 subscales: skill discretion or the level of skill and creativity required on the job and decision authority or the possibilities for workers to make decisions about their work. An example item is: "My job allows me to take my own decisions." The Cronbach's $\alpha$ of the job control scale was 0.80 .

The 3rd dimension of social support in the workplace also consisted of the sum score of 2 subscales, each containing 4 items: supervisor support and coworker support. An example item is: "My supervisor is concerned about me." The Cronbach's $\alpha$ of the social support scale was 0.84 . Effort was assessed through 5 items, measuring demanding aspects of the work environment. An example item for this scale is: "I am often pressured to work overtime." The Cronbach's $\alpha$ of this scale was 0.75 .

Reward was measured by 11 items, containing financial reward, esteem, career opportunities and job security. An example item is: "My job promotion prospects are poor." The Cronbach's $\alpha$ of the rewards scale was 0.90 . 
Bullying was questioned using 9 items referring mainly to isolation, destabilization and threat to personal standing, based on the scale of Quine [38]. An example item is: "At my work, necessary information is withheld from me." The Cronbach's $\alpha$ of the bullying scale was 0.90 .

Response categories on every question were: "yes, absolutely," "rather yes," "rather no," "absolutely not."

To assess work-family conflict, 2 measures based on the questionnaire developed by Kelloway et al. were used [39]. Strain based work-to-home conflict (WHC), or the extent to which work interferes with the responsibilities at home (example item: "I have to change family plans due to demands at work") and home-to-work conflict (HWC), or the extent to which private life interferes with work (example item: "My day at work is regularly interrupted by family duties") were measured. Both constructs were defined by the sum score of 6 items, which were each scored with 5 response categories. The Cronbach's $\alpha$ was respectively 0.82 and 0.83 for the WHC and HWC scales.

Since psychosocial variables demonstrated a skewed distribution in order to improve interpretability of the results, dichotomous variables were created. For all the psychosocial factors, except for bullying, the median split procedure with medians included in the higher scores was applied, in line with earlier studies in this research domain [35]. Given that the median of the bullying scale corresponds to 12 , which is a low score on a range between 0 (no bullying) and 36 (extreme bullying), we defined the upper quartile of the distribution as those being a victim of bullying, which is also more consistent with the prevalence of bullying reported in the literature [40].

\section{Confounding factors}

Several individual and socio-demographic variables were questioned, including: age, gender, educational level and work sector. Low educational level was defined as graduating from a primary school or an incomplete secondary school, medium education was defined as graduating from a secondary school, and high education as completing a high school or a university. The sector was divided in the (semi-)public sector, social work and healthcare sector, and the secondary sector comprising a manufacturing company. A question regarding seniority in the present firm was included in the survey ( $\leq 5$ years $/>5$ years). The respondents were questioned about several health indicators and behaviors, such as current smoking habits (yes/no), self-reported weight and height, and self-rated health. Body Mass Index (BMI) was calculated as weight divided by the squared height $\left(\mathrm{kg} / \mathrm{m}^{2}\right)$. Self-rated health was evaluated by the following question: "How do you generally assess your health?" with 5 response categories. The variable was dichotomized: very good or good versus average, bad or very bad.

To evaluate the amount of stress outside work, a 9-item based scale regarding problems in private life was used [41]. A worker indicated on a 4-point Likert scale how often during the last month she or he had to deal with the following problems: financial problems, relational problems with partner, problems with children, relational problems with family and friends, health problems in a family, problems with child care, problems related to transport, sexual problems, other problems outside work. A sum score was calculated, with lower scores meaning fewer problems outside work.

Neuroticism, as an indicator of negative affectivity, was measured using a scale derived from the NEO (Neuroticism, Extraversion, Openness to Experience) Five-Factor Personality Inventory, consisting of 12 items [42]. The respondents were asked to rate on a 5-point Likert-type scale, the extent to which each statement corresponded to their perception of themselves.

\section{Statistical analyses}

$\mathrm{Chi}^{2}$ tests or t-tests were conducted to assess gender differences in socio-demographic, health behavior and psychosocial work characteristics. 
The relationship between psychosocial factors and presenteeism was examined using the multiple logistic regression analysis. In the 1st model, crude odds ratios (OR) with $95 \%$ confidence intervals (CI) were calculated. In the next step, the odds ratios were adjusted for several confounders, which are known risk factors for presenteeism. The following covariates were considered: age, gender, educational level, stress outside work, neuroticism, sector, seniority and several health-related confounders (smoking, BMI and self-rated health). In the 3rd multiple model, all psychosocial factors were entered simultaneously.

Finally, an additional analysis was conducted in a subgroup of workers with good self-rated health and low neuroticism, defined as the lower $75 \%$ of the distribution on the neuroticism scale. This procedure was followed as preliminary analyses revealed that self-rated health and neuroticism accounted for a large part of the confounding. This allowed getting a more precise idea about the strength of associations. No significant interaction effects were observed between psychosocial factors and gender in the relation with presenteeism. Therefore, the analyses were not stratified for gender.

The models were screened for multicollinearity according to the calculation of Variance Inflation Factors, which revealed no problems. All the models were evaluated at a $5 \%$ significance level $(\mathrm{p}<0.05)$. Data processing was performed using SPSS 21.0 software.

\section{RESULTS}

Description of socio-demographic variables, presenteeism, health-related variables and psychosocial variables is presented in Table 1. About $50 \%$ of the workers reported coming to work despite illness 2-5 times or more during the past year. The women reported significantly more presenteeism, high job demands, low control, high WHC and HWC, while the men reported more bullying.

Table 2 presents some descriptive information about the subgroup with good health and low neuroticism. Those workers not only reported significantly less presenteeism, but also less exposure to psychosocial risk factors.

The results of the univariate analysis showed a significant association between presenteeism and all the considered psychosocial factors, except for job control (Table 3).

After adjustment for several confounders, the relationship between HWC and presenteeism was no longer significant, and no important changes could be detected for the other psychosocial factors. Both high job demands $(\mathrm{OR}=1.64$, 95\% CI: $1.39-1.93)$ and high efforts $(\mathrm{OR}=1.69$, 95\% CI: 1.43-2.01) were associated with presenteeism. Furthermore, low support (OR $=1.24,95 \% \mathrm{CI}$ : 1.05-1.46) and low rewards $(\mathrm{OR}=1.53,95 \% \mathrm{CI}: 1.3-1.81)$ were significantly related to presenteeism. A significant relationship was also observed between high levels of bullying $(\mathrm{OR}=1.32$, 95\% CI: 1.09-1.61) and presenteeism. Finally, the workers reporting high levels of $\mathrm{WHC}(\mathrm{OR}=1.84,95 \%$ CI: 1.54 2.2) also demonstrated more presenteeism.

The 3rd multiple model, in which all psychosocial factors were entered simultaneously, revealed that high efforts, low rewards and high WHC were independently and significantly related to presenteeism.

From the subgroup analysis on the workers with good selfrated health and low neuroticism (Table 4), highly similar results were derived.

In the multiple model, in which adjustments for the other psychosocial risk factors were made, only high WHC remained significantly associated with presenteeism.

\section{DISCUSSION}

This study aimed at investigating the relationship between several classical and some more emerging types of psychosocial risk factors, such as bullying and work-family conflict, and presenteeism. We observed that both work content and contextual psychosocial factors were significantly related to presenteeism.

Our study results demonstrated that high job demands and efforts were positively correlated with presenteeism, 
Table 1. Socio-demographics, presenteeism and psychosocial characteristics

\begin{tabular}{|c|c|c|c|c|}
\hline \multirow[b]{2}{*}{ Variable } & \multicolumn{3}{|c|}{ Respondents } & \multirow[b]{2}{*}{$\mathrm{p}^{\mathrm{a}}$} \\
\hline & $\begin{array}{c}\text { total } \\
(\mathrm{N}=2983)\end{array}$ & $\begin{array}{c}\text { men } \\
(\mathrm{N}=1372)\end{array}$ & $\begin{array}{c}\text { women } \\
(\mathrm{N}=1611)\end{array}$ & \\
\hline Age [years] $(\mathrm{M} \pm \mathrm{SD})$ & $43.3 \pm 6.7$ & $43.5 \pm 6.7$ & $43.2 \pm 6.8$ & 0.120 \\
\hline Educational level [n (\%)] & & & & $<0.001$ \\
\hline low & $617(20.8)$ & $353(25.8)$ & $264(16.5)$ & \\
\hline medium & $1031(34.7)$ & $467(34.2)$ & $564(35.2)$ & \\
\hline high & $1323(44.5)$ & $547(40.0)$ & $776(48.4)$ & \\
\hline Sector $[\mathrm{n}(\%)]$ & & & & $<0.001$ \\
\hline public & $1591(53.3)$ & $988(72.0)$ & $603(37.4)$ & \\
\hline healthcare and social & $1161(38.9)$ & $227(16.5)$ & $934(58.0)$ & \\
\hline secondary & $231(7.7)$ & $157(11.4)$ & $74(4.6)$ & \\
\hline Smoking [n (\%)] & $816(27.6)$ & $380(27.8)$ & $436(27.3)$ & 0.760 \\
\hline Neuroticism [n (\%)] & & & & $<0.001$ \\
\hline low & $2272(76.7)$ & $1140(83.3)$ & $1132(70.9)$ & \\
\hline high & $692(23.3)$ & $228(16.7)$ & $464(29.1)$ & \\
\hline $\mathrm{BMI}\left[\mathrm{kg} / \mathrm{m}^{2}\right](\mathrm{M} \pm \mathrm{SD})$ & $25.2 \pm 4.1$ & $25.9 \pm 3.5$ & $24.5 \pm 4.4$ & $<0.001$ \\
\hline Self-rated health [n (\%)] & & & & $<0.010$ \\
\hline good / very good & $1995(67.9)$ & $954(70.4)$ & $1041(65.8)$ & \\
\hline average / bad / very bad & $943(32.1)$ & $401(29.6)$ & $542(34.2)$ & \\
\hline Seniority $[\mathrm{n}(\%)]$ & & & & $<0.001$ \\
\hline$\leq 5$ years & $328(11.0)$ & $119(8.7)$ & $209(13.1)$ & \\
\hline$>5$ years & $2642(89.0)$ & $1250(91.3)$ & $1392(86.9)$ & \\
\hline Presenteeism [n (\%)] & & & & $<0.001$ \\
\hline never & $576(19.6)$ & $335(24.7)$ & $241(15.3)$ & \\
\hline 1 time & $872(29.7)$ & $411(30.3)$ & $461(29.3)$ & \\
\hline $2-5$ times & $1246(42.5)$ & $537(39.5)$ & $709(45.0)$ & \\
\hline$>5$ times & $239(8.1)$ & $75(5.5)$ & $164(10.4)$ & \\
\hline High job demands [n (\%)] & $1506(50.9)$ & $635(46.6)$ & $871(54.5)$ & $<0.001$ \\
\hline Low job control [n (\%)] & $1475(49.9)$ & $596(43.7)$ & $879(55.2)$ & $<0.001$ \\
\hline Low social support [n (\%)] & $1170(39.7)$ & $533(39.1)$ & $637(40.3)$ & 0.520 \\
\hline High efforts $[\mathrm{n}(\%)]$ & $1719(59.7)$ & $807(60.4)$ & $912(59.0)$ & 0.430 \\
\hline Low rewards $[\mathrm{n}(\%)]$ & $1383(47.9)$ & $666(49.5)$ & $717(46.5)$ & 0.110 \\
\hline High work-to-home conflict [n (\%)] & $1509(50.9)$ & $635(46.4)$ & $874(54.8)$ & $<0.001$ \\
\hline High home-to-work conflict [n (\%)] & $1483(50.0)$ & $620(45.3)$ & $863(54.1)$ & $<0.001$ \\
\hline Bullying [n (\%)] & $771(26.6)$ & $383(28.6)$ & $388(24.9)$ & 0.026 \\
\hline
\end{tabular}

M - mean; SD - standard deviation.

${ }^{a}$ Gender difference. Results of $\mathrm{t}$-test or $\mathrm{Chi}^{2}$ test. 
Table 2. Socio-demographics, presenteeism and psychosocial characteristics for the subgroup with good health and low neuroticism

\begin{tabular}{|c|c|c|c|}
\hline \multirow[b]{2}{*}{ Variable } & \multicolumn{2}{|c|}{ Respondents } & \multirow[b]{2}{*}{$\mathrm{p}^{\mathrm{a}}$} \\
\hline & $\begin{array}{c}\text { subgroup: } \\
\text { good health / low neuroticism } \\
(\mathrm{N}=1666)\end{array}$ & $\begin{array}{c}\text { rest } \\
(\mathrm{N}=1274)\end{array}$ & \\
\hline Age [years] $(\mathrm{M} \pm \mathrm{SD})$ & $42.6 \pm 6.7$ & $44.2 \pm 6.6$ & $<0.001$ \\
\hline Gender $[\mathrm{n}(\%)]$ & & & $<0.001$ \\
\hline men & $861(51.7)$ & $494(38.8)$ & \\
\hline women & $805(48.3)$ & $780(61.2)$ & \\
\hline Educational level [n (\%)] & & & $<0.001$ \\
\hline low & $304(18.4)$ & $296(23.4)$ & \\
\hline medium & $549(33.1)$ & $473(37.3)$ & \\
\hline high & $807(48.6)$ & $498(39.3)$ & \\
\hline Smoking [n (\%)] & $390(23.5)$ & $418(33.1)$ & $<0.001$ \\
\hline $\mathrm{BMI}\left[\mathrm{kg} / \mathrm{m}^{2}\right](\mathrm{M} \pm \mathrm{SD})$ & $24.7 \pm 3.7$ & $25.6 \pm 4.5$ & $<0.001$ \\
\hline Seniority [n (\%)] & & & 0.005 \\
\hline$\leq 5$ years & $207(12.5)$ & $116(9.2)$ & \\
\hline$>5$ years & $1454(87.5)$ & $1151(90.8)$ & \\
\hline Presenteeism [n (\%)] & & & $<0.001$ \\
\hline $0-1$ time & $983(59.7)$ & $450(36.0)$ & \\
\hline$\geq 2$ times & $663(40.3)$ & $799(64.0)$ & \\
\hline High job demands [n (\%)] & $763(46.1)$ & $726(57.5)$ & $<0.001$ \\
\hline Low job control $[\mathrm{n}(\%)]$ & $717(43.3)$ & $736(58.4)$ & $<0.001$ \\
\hline Low social support [n (\%)] & $517(31.3)$ & $640(51.1)$ & $<0.001$ \\
\hline High efforts $[\mathrm{n}(\%)]$ & $928(57.5)$ & $774(62.9)$ & 0.003 \\
\hline Low rewards [n (\%)] & $606(37.3)$ & $764(62.3)$ & $<0.001$ \\
\hline High work-to-home conflict [n (\%)] & $629(37.9)$ & $865(68.4)$ & $<0.001$ \\
\hline High home-to-work conflict [n (\%)] & $701(42.2)$ & $761(60.2)$ & $<0.001$ \\
\hline Bullying [n (\%)] & $301(18.5)$ & $465(37.7)$ & $<0.001$ \\
\hline
\end{tabular}

Abbreviations as in Table 1.

${ }^{a}$ Difference between the groups. Results of t-test or $\mathrm{Chi}^{2}$ test.

Table 3. Association between psychosocial characteristics and presenteeism, using logistic the regression analysis $(\mathrm{N}=2983)$

\begin{tabular}{lllllll}
\hline \multirow{2}{*}{ Variable } & \multicolumn{2}{c}{ Crude model } & \multicolumn{2}{c}{ Adjusted model $^{\mathrm{a}}$} & \multicolumn{2}{c}{ Adjusted model $^{\mathrm{b}}$} \\
\cline { 2 - 7 } & OR & $95 \% \mathrm{CI}$ & OR & $95 \%$ CI & OR & $95 \%$ CI \\
\hline Job demands & & & & & & \\
low & 1.00 & & 1.00 & & 1.00 & \\
high & $1.82^{* * *}$ & $1.57-2.11$ & $1.64^{* * *}$ & $1.39-1.93$ & 1.21 & $1.00-1.49$ \\
\hline
\end{tabular}


Table 3. Association between psychosocial characteristics and presenteeism, using the logistic regression analysis $(\mathrm{N}=2983)$ - cont.

\begin{tabular}{|c|c|c|c|c|c|c|}
\hline \multirow{2}{*}{ Variable } & \multicolumn{2}{|c|}{ Crude model } & \multicolumn{2}{|c|}{ Adjusted model $^{\mathrm{a}}$} & \multicolumn{2}{|c|}{ Adjusted model $^{\mathrm{b}}$} \\
\hline & OR & $95 \% \mathrm{CI}$ & OR & $95 \% \mathrm{CI}$ & OR & $95 \% \mathrm{CI}$ \\
\hline \multicolumn{7}{|l|}{ Control } \\
\hline low & 1.00 & & 1.00 & & 1.00 & \\
\hline high & 0.88 & $0.76-1.02$ & 1.14 & $0.96-1.35$ & 1.10 & $0.91-1.32$ \\
\hline \multicolumn{7}{|l|}{ Social support at work } \\
\hline high & 1.00 & & 1.00 & & 1.00 & \\
\hline low & $1.59^{* * *}$ & $1.37-1.85$ & $1.24^{*}$ & $1.05-1.46$ & 0.98 & $0.81-1.20$ \\
\hline \multicolumn{7}{|l|}{ Effort } \\
\hline low & 1.00 & & 1.00 & & 1.00 & \\
\hline high & $1.63^{* * *}$ & $1.40-1.90$ & $1.69^{* * *}$ & $1.43-2.01$ & $1.34^{* *}$ & $1.09-1.65$ \\
\hline \multicolumn{7}{|l|}{ Reward } \\
\hline high & 1.00 & & 1.00 & & 1.00 & \\
\hline low & $1.96^{* * *}$ & $1.68-2.27$ & $1.53^{* * *}$ & $1.30-1.81$ & $1.42^{* *}$ & $1.17-1.74$ \\
\hline \multicolumn{7}{|l|}{ Bullying } \\
\hline no & 1.00 & & 1.00 & & 1.00 & \\
\hline yes & $1.79 * * *$ & $1.51-2.12$ & $1.32^{* *}$ & $1.09-1.61$ & 1.09 & $0.88-1.36$ \\
\hline \multicolumn{7}{|c|}{ Home-to-work conflict } \\
\hline low & 1.00 & & 1.00 & & 1.00 & \\
\hline high & $1.44 * * *$ & $1.25-1.67$ & 1.01 & $0.85-1.19$ & 0.97 & $0.81-1.17$ \\
\hline \multicolumn{7}{|c|}{ Work-to-home conflict } \\
\hline low & 1.00 & & 1.00 & & 1.00 & \\
\hline high & $2.46^{* * * *}$ & $2.12-2.86$ & $1.84^{* * *}$ & $1.54-2.20$ & $1.61^{* * *}$ & $1.32-1.96$ \\
\hline
\end{tabular}

$\mathrm{N}$ - respondents; OR - odds ratio; $\mathrm{CI}$ - confidence interval.

$* \mathrm{p}<0.05 ; * \mathrm{p}<0.01 ; * * * \mathrm{p}<0.001$.

${ }^{\text {a }}$ Model is adjusted for gender, age, educational level, seniority, sector, smoking, body mass index, self-rated health, stress outside work, neuroticism.

${ }^{\mathrm{b}}$ Multiple model, including all psychosocial characteristics.

Table 4. Association between psychosocial characteristics and presenteeism, using the logistic regression analysis on the selection of workers with good or very good self-rated health and low neuroticism ( $\mathrm{N}=1666)$

\begin{tabular}{lcccccc}
\hline \multirow{2}{*}{ Variable } & \multicolumn{2}{c}{ Crude model } & \multicolumn{2}{c}{ Adjusted model $^{\mathrm{a}}$} & \multicolumn{2}{c}{ Adjusted model $^{\mathrm{b}}$} \\
\cline { 2 - 6 } & OR & $95 \% \mathrm{CI}$ & OR & $95 \%$ CI & OR & $95 \%$ CI \\
\hline Job demands & & & & & & \\
$\quad$ low & 1.00 & & 1.00 & & 1.00 & \\
$\quad$ high & $1.45^{* * *}$ & $1.19-1.76$ & $1.38^{* *}$ & $1.12-1.72$ & 1.07 & $0.82-1.39$ \\
Control & & & & & & \\
$\quad$ low & 1.00 & & 1.00 & & 1.00 & \\
high & 0.99 & $0.81-1.21$ & 1.12 & $0.90-1.39$ & 1.14 & $0.89-1.46$ \\
\hline
\end{tabular}


Table 4. Association between psychosocial characteristics and presenteeism, using the logistic regression analysis on the selection of workers with good or very good self-rated health and low neuroticism $(\mathrm{N}=1666)-$ cont.

\begin{tabular}{|c|c|c|c|c|c|c|}
\hline \multirow{2}{*}{ Variable } & \multicolumn{2}{|c|}{ Crude model } & \multicolumn{2}{|c|}{ Adjusted model $^{\mathrm{a}}$} & \multicolumn{2}{|c|}{ Adjusted model $^{\mathrm{b}}$} \\
\hline & OR & $95 \% \mathrm{CI}$ & OR & $95 \% \mathrm{CI}$ & OR & $95 \% \mathrm{CI}$ \\
\hline \multicolumn{7}{|l|}{ Social support at work } \\
\hline high & 1.00 & & 1.00 & & 1.00 & \\
\hline low & $1.43^{* *}$ & $1.16-1.76$ & $1.30^{*}$ & $1.01-1.63$ & 1.08 & $0.83-1.41$ \\
\hline \multicolumn{7}{|l|}{ Effort } \\
\hline low & 1.00 & & 1.00 & & 1.00 & \\
\hline high & $1.40 * *$ & $1.14-1.71$ & $1.39^{*}$ & $1.11-1.74$ & 1.18 & $0.90-1.55$ \\
\hline \multicolumn{7}{|l|}{ Reward } \\
\hline high & 1.00 & & 1.00 & & 1.00 & \\
\hline low & $1.48^{* * *}$ & $1.20-1.82$ & $1.36^{* *}$ & $1.09-1.69$ & 1.15 & $0.89-1.50$ \\
\hline \multicolumn{7}{|l|}{ Bullying } \\
\hline no & 1.00 & & 1.00 & & 1.00 & \\
\hline yes & $1.70^{* * *}$ & $1.32-2.19$ & $1.49^{* *}$ & $1.13-1.95$ & 1.32 & $0.97-1.79$ \\
\hline \multicolumn{7}{|l|}{ Home-to-work conflict } \\
\hline low & 1.00 & & 1.00 & & 1.00 & \\
\hline high & $1.46^{* * *}$ & $1.19-1.78$ & 1.17 & $0.93-1.46$ & 1.14 & $0.90-1.45$ \\
\hline \multicolumn{7}{|c|}{ Work-to-home conflict } \\
\hline low & 1.00 & & 1.00 & & 1.00 & \\
\hline high & $2.02^{* * *}$ & $1.65-2.48$ & $1.85^{* * *}$ & $1.47-2.34$ & $1.69^{* * *}$ & $1.31-2.18$ \\
\hline
\end{tabular}

Abbreviations as in Table 3.

$* \mathrm{p}<0.05 ; * \mathrm{p}<0.01 ; * * \mathrm{p}<0.001$.

${ }^{a}$ Model is adjusted for gender, age, educational level, seniority, sector, smoking, body mass index, stress outside work, neuroticism.

${ }^{\mathrm{b}}$ Multiple model, including all psychosocial characteristics.

which suggests that employees will work while sick as a short-time strategy to avoid a decrement of productivity, which is actually in line with earlier research [5,20,21]. We were not able to demonstrate a significant relationship between job control and presenteeism in our study sample. Also in former studies, results with respect to this psychosocial factor are inconsistent and, as mentioned by Aronsson and Gustafsson [5], it is rather difficult to predict the specific relationship between control and presenteeism. On the one hand, high control is considered to be a risk for presenteeism, since workers in high control jobs may be able to adjust their work situation to their current physical and mental capabilities [23]. On the other hand, low control jobs are generally regarded as "less healthy" jobs and, therefore, presenteeism may be a proxy for the health status of a worker. Nevertheless, we were not able to find a significant association between control and presenteeism, neither in the complete group, nor in the subgroup of healthy workers [43].

Low rewards were significantly related to presenteeism in the workers. Rewards in the ERI model relate to financial reward, esteem, career opportunities and job security. Especially job insecurity has been demonstrated to be significantly related to presenteeism in former research [23]. Alongside, also financial situation is likely to affect an employee's decision whether to stay at home or to go to 
work when sick $[3,5]$. Therefore, low rewards may stimulate a worker to choose for presenteeism in case of illness. Low social support was significantly associated with presenteeism, which generally confirms earlier research demonstrating social support as an important feature of the psychosocial work environment, which influences the attendance behavior of a worker [25,44]. However, former results are inconclusive whether lack of social support or high social support is associated with presenteeism $[11,25,44]$. Low support was proposed as a risk factor for presenteeism in the way that workers fear taking sickness absence [25]. Furthermore, high support in the workplace was suggested to "promote" early return to work and thus, presenteeism, which is in contrast with our results [25]. Finally, a recent study has demonstrated that a supervisor's support is acting as a buffering mechanism in the relationship between presenteeism and exhaustion [11].

To our knowledge, the specific relationship between bullying and presenteeism has not been extensively investigated before [32]. In our study sample, bullying was significantly and positively related to presenteeism. A possible explanation for this finding may be the use of the bullying instrument, which is specifically assessing the dimensions of isolation, destabilization and threat to personal standing, and does not refer to any dimension of harassment [38]. It is, therefore, possible, that someone who feels a victim of this kind of bullying behavior, feels fear to choose for sickness absence and will likely prefer presenteeism to avoid further isolation and destabilization. Another possible explanation for this result can be found in the health status of a worker: victims of bullying may be in a worse health status, which, therefore, leads to higher presenteeism [34]. While the impact of family responsibilities on work and sickness absence has been a subject of investigation in earlier research $[33,45,46]$, the relationship with presenteeism has been seldom examined [34]. Generally, it has been demonstrated that HWC or the situation in which the family circumstances interfere with the work role represents a risk factor for sickness absence [33]. In this perspective, it is assumed that high HWC would not be or would be negatively correlated with presenteeism [34], which was confirmed in both the total group and the subgroup, revealing no significant relationship between high HWC and presenteeism. The relationship between the other direction of the work family conflict, namely high WHC and presenteeism was also expected and established in an earlier study [34]. Someone experiencing duties at work that interfere with the family responsibilities, will rather choose for presenteeism when sick.

The multiple model, in which all psychosocial factors were entered simultaneously, revealed that high efforts and low rewards were independently related to presenteeism, suggesting that the ERI-model of Siegrist et al. [36] may be particularly valuable in identifying psychosocial risk factors for presenteeism. Furthermore, also high WHC remained significant in the final multiple model, underlining the importance of this specific factor. The subgroup analysis roughly yielded similar results with respect to high WHC. Rewards were not significantly related to presenteeism anymore in this subgroup, which is possibly due to the fact that the workers with good self-rated health had significantly more high rewards in comparison with those with average or bad self-rated health.

Although gender differences were demonstrated in both psychosocial factors and presenteeism, no significant interaction effects between psychosocial factors and gender in relation to presenteeism could be revealed. Therefore, the analyses were not conducted separately for the men and women. Moreover, additional analyses, stratified for gender (results not shown), yielded highly similar results. Although this study extends the existing literature on presenteeism, several limitations have to be mentioned.

The main limitation consists in the cross-sectional design using self-reported measures, which restricts the conclusion and does not allow to provide causal explanations. 
Nevertheless, several precautionary measures were taken to reduce common method bias in our results: confidentiality was guaranteed to lower social desirable answers, the relations were adjusted for a measure of negative affectivity and additional subgroup analyses were conducted on a limited sample with low neuroticism and good selfrated health. Moreover, in contrast with sickness absence measures, it is quite challenging to obtain objectively registered presenteeism figures, and almost all studies investigating presenteeism are based on self-reports [2]. The use of a single item questionnaire for the assessment of presenteeism, which could be affected by recall bias, is another limitation that should be mentioned. However, this single question has been applied by several former investigators, suggesting similar presenteeism frequencies $[4,8,15,21,23]$. Furthermore, sensitivity analyses, with alternative cut-off points for defining presenteeism (> 1 time going at work despite illness; $>5$ times going at work despite illness) lead to roughly similar results, consequently underlining our conclusions.

The 2nd limitation is the relatively low response rate, which possibly leads to a selection bias in the population. Unfortunately, we were not able to examine whether the non-respondents differed from the respondents regarding psychosocial factors or presenteeism. Although no important differences in the age and gender were discovered, caution should be made in generalization of the results. Additionally, it should be noted that the Belstress III study does not consist of a representative sample of the Belgian working population. Nevertheless, this is less important in analytical studies like this one, where possible relationships are examined [47].

Although adjustments were made for several confounding factors, including neuroticism as a personality trait, it is quite imaginable that some important confounders were not measured, and supplementary adjustments may have resulted in different findings. For instance, no information was available on the application of specific sickness management strategies in the companies nor about the attitudes of the workers towards their health and sickness absence. These are issues which may confound the results and are not fully captured by the confounding variables, that we had information on.

Finally, the use of dichotomous exposure variables, which may cause a loss of information due to categorization, can be a subject of debate. However, this decision was made due to some psychosocial variables being highly skewed and in order to make the odds ratios easier to interpret. Moreover, the additional analysis performed with continuous psychosocial variables, resulted in similar conclusions. The major strength of our study is that, besides adjustment for self-rated health and several lifestyle variables, we also adjusted the models for neuroticism, which is a personality trait referring to a tendency to experience a negative affect [42]. This personality trait is expected to be involved in the reaction on job stressors [48]. Furthermore, in a preliminary analysis, neuroticism was significantly correlated with presenteeism, which additionally emphasizes the importance of treating this personality factor as a major confounder. Also the additional subgroup analysis involving the workers with good self-rated health and low neuroticism underlines the strength of our results, since no important changes could be revealed between the results of the subgroup analysis and the analysis on the whole group.

\section{CONCLUSIONS}

In conclusion, our study demonstrates that both job content related factors as well as work contextual psychosocial factors were significantly related to presenteeism. This independent relationship between psychosocial factors and presenteeism was not only demonstrated on the total group of workers, but also on a selection of workers with good self-rated health and low neuroticism, which, therefore, underlines the importance of these factors in the attendance behavior. Hence, our results highlight 
a multidimensional nature of this phenomenon by demonstrating the importance of the work environment in the attendance behavior of an individual worker.

Some recommendations can be made for further research. In order to reveal the relationship between psychosocial factors and the attendance behavior of an employee, both presenteeism and sickness absence figures should be considered together in a longitudinal study. This should enable getting more insight into the effect of specific psychosocial factors on the decision making of ill workers whether to stay at home or to go to work. In addition, it is also recommended to study the association of physical demands and ergonomic preventive measures on the attendance behavior.

The main implication for practice is that presenteeism, which is a behavior of a worker with possible negative consequences for both - an individual worker and an employer, is not purely driven by the health status of a worker, but several psychosocial factors also play an important role.

This specific knowledge may be of great importance to direct policies and management strategies aiming at reduction of costs related to sickness absence and presenteeism.

\section{REFERENCES}

1. McKevitt C, Morgan M, Dundas R, Holland W. Sickness absence and "working through" illness: A comparison of two professional groups. J Public Health Med. 1997;19:295-300, http://dx.doi.org/10.1093/oxfordjournals.pubmed.a024633.

2. Johns G. Presenteeism in the workplace: A review and research agenda. J Organ Behav. 2010;31:519-42, http://dx.doi. org/10.1002/job.630.

3. Aronsson G, Gustafsson K, Dallner M. Sick but yet at work. An empirical study of sickness presenteeism. J Epidemiol Community Health. 2000;54(7):502-9, http://dx.doi. org/10.1136/jech.54.7.502.

4. Boles M, Pelletier B, Lynch W. The relationship between health risk and work productivity. J Occup Environ Med. 2004;46:737-45, http://dx.doi.org/10.1097/01.jom.0000 131830.45744.97.
5. Aronsson G, Gustafsson K. Sickness presenteeism: Prevalence, attendance-pressure factors, and an outline of a model for research. J Occup Environ Med. 2005;47(9):958-66, http://dx.doi.org/10.1097/01.jom.0000177219.75677.17.

6. McEwen BS. Protection and damage from acute and chronic sterss: Allostasis and allostatic overload and relevance to the pathophysiology of psychiatric disorders. Ann N Y Acad Sci. 2004;1032:1-7, http://dx.doi.org/10.1196/ annals.1314.001.

7. Westerlund H, Kivimäki M, Ferrie J, Marmot M, Shipley M, Vahtera J, et al. Does working while ill trigger serious coronary events? The Whitehall II Study. J Occup Environ Med. 2009;51(9):1099-104, http://dx.doi.org/10.1097/ JOM.0b013e3181b350e1.

8. Bergström G, Bodin L, Haghberg J, Lindh T, Aronsson G, Josephson M. Does sickness presenteeism have an impact on future general health? Int Arch Occup Environ Health. 2009;82(10):1179-90, http://dx.doi.org/10.1007/s00 420-009-0433-6.

9. Gustafsson K, Marklund S. Consequences of sickness presence and sickness absence on health and work ability: A Swedish prospective cohort study. Int J Occup Med Environ Health. 2011;24:153-65, http://dx.doi.org/10.2478/ s13382-011-0013-3.

10. Demerouti E, le Blanc PM, Bakker AM, Schaufeli WB, Hox J. Present but sick: A three-wave study on job demands, presenteeism and burn-out. Career Dev Int. 2009;14(1): 50-68, http://dx.doi.org/10.1108/13620430910933574.

11. Lu L, Cooper CL, Lin HY. A cross-cultural examination of presenteeism and supervisory support. Career Dev Int. 2013;18(5):440-56, http://dx.doi.org/10.1108/CDI-032013-0031.

12. Lu L, Lin HY. Unhealthy and present: Motives and consequences of the act of presenteeism among Taiwanese employees. J Occup Health Psychol. 2013;18(4):406-16, http:// dx.doi.org/10.1037/a0034331.

13. Conway PM, Hogh A, Rugulies R, Hansen AM. Is sickness presenteeism a risk factor for depression? A Danish 2-year 
follow-up study. J Occup Environ Med. 2014;56(6):595-602, http://dx.doi.org/10.1097/JOM.0000000000000177.

14. Tayloan M, Aronsson G, Leineweber C, Hanson LM, Alexanderson K, Westerlund $\mathrm{H}$. Sickness presenteeism predicts suboptimal self-rated health and sickness absence: A Nationally representative study of the Swedish working population. PLoS One. 2012;7(9):e44721, http://dx.doi.org/10.1371/ journal.pone.0044721.

15. Bergström G, Bodin L, Haghberg J, Aronsson G, Josephson M. Sickness presenteeism today, sickness absenteeism tomorrow? A prospective study on sickness presenteeism and future sickness absenteeism. J Occup Environ Med. 2009;51(6): 629-38, http://dx.doi.org/10.1097/JOM.0b013e3181a8281b.

16. Janssens H, Clays E, de Clercq B, de Bacquer D, Braeckman $\mathrm{L}$. The relation between presenteeism and different types of future sickness absence. J Occup Health. 2013;55 (3):132-41, http://dx.doi.org/10.1539/joh.12-0164-OA.

17. Goetzel R, Long S, Ozminkowski R, Hawkins K, Wang S, Lynch W. Health, absence, disability, and presenteeism cost estimates of certain physical and mental health conditions affecting U.S. employers. J Occup Environ Med. 2004;46(4):398412, http://dx.doi.org/10.1097/01.jom.0000121151.40413.bd.

18. Stewart W, Ricci J, Chee E, Morganstein D. Lost productive work time costs from health conditions in the United States: Results from the American Productivity Audit. J Occup Environ Med. 2003;45(12):1234-46, http://dx.doi. org/10.1097/01.jom.0000099999.27348.78.

19. Van den Heuvel S, Geuskens G, Hooftman W, Koppes L, van den Bossche S. Productivity loss at work; health-related and work-related factors. J Occup Rehabil. 2010;20(3): 331-9, http://dx.doi.org/10.1007/s10926-009-9219-7.

20. Kivimäki M, Head J, Ferrie JE, Hemingway H, Shipley M, Vahtera $\mathrm{J}$, et al. Working while ill as a risk factor for serious coronary events: The Whitehall II study. Am J Public Health. 2005;95:98-102, http://dx.doi.org/10.2105/AJPH. 2003.035873.

21. Elstad J, Vabo M. Job stress, sickness absence and sickness presenteeism in the Nordic elderly care. Scand J Public
Health. 2008;36(5):467-74, http://dx.doi.org/10.1177/1403 494808089557.

22. Böckerman P, Laukkanen E. What makes you work while you are sick? Evidence from a survey of workers. Eur J Public Health. 2010;20(1):43-6, http://dx.doi.org/10.1093/eurpub/ckp076.

23. Heponiemi T, Elovaionio M, Pentti J, Virtanen M, Westerlund $\mathrm{H}$, Virtanen P, et al. Association of contractual and subjective job insecurity with sickness presenteeism among public sector employees. J Occup Environ Med. 2010;52(8): 830-5, http://dx.doi.org/10.1097/JOM.0b013e3181ec7e23.

24. Johansson G, Lundberg I. Adjustment latitude and attendance requirements as determinants of sickenss absence or attendance. Empirical tests of the illness flexibility model. Soc Sci Med. 2004;58:1857-68, http://dx.doi.org/10.1016/ S0277-9536(03)00407-6.

25. Baker-McClearn D, Greasley K, Dale J, Griffith F. Absence management and presenteeism: The pressures on employees to attend work and the impact of attendance on performance. Hum Resour Manag J. 2009;20(3):311-28, http:/ dx.doi.org/10.1111/j.1748-8583.2009.00118.x.

26. Kivimäki M, Elovainio M, Vahtera J. Workplace bullying and sickness absence in hospital staff. Occup Environ Med. 2000;57(10):656-60, http://dx.doi.org/10.1136/oem.57. 10.656 .

27. Clausen T, Hogh A, Borg V. Acts of offensive behaviour and risk of long-term sickness absence in the Danish elder-care services: A prospective analysis of register-based outcomes. Int Arch Occup Environ Health. 2012;85(4):381-7, http:// dx.doi.org/10.1007/s00420-011-0680-1.

28. Ortega A, Christensen KB, Hogh A, Rugulies R, Borg V. One-year prospective study on the effect of workplace bullying on long-term sickness absence. J Nurs Manag. 2011;19:752-9, http://dx.doi.org/10.1111/j.1365-2834.2010.01179.x.

29. Niedhammer I, David S, Degioanni S. Association between workplace bullying and depressive symptoms in the French working population. J Psychosom Res. 2006;61(2):251-9, http://dx.doi.org/10.1016/j.jpsychores.2006.03.051. 
30. Niedhammer I, David S, Degioanni S, Drummond A, Philip P, Acquarone D, et al. Workplace bullying and sleep disturbances: Findings from a large scale cross-sectional survey in the French working population. Sleep. 2009;32(9):1211-9.

31. Kivimäki M, Virtanen M, Vartia M, Elovainio M, Vahtera J, Keltikangas-Järvinen L. Workplace bullying and the risk of cardiovascular disease and depression. Occup Environ Med. 2003;60(10):779-83, http://dx.doi.org/10.1136/oem.60.10.779.

32. Eurofound. Fifth European Working Conditions Survey. Luxembourg: Publications Office of the European Union; 2012.

33. Clays E, Kittel F, Godin I, de Bacquer D, de Backer G. Measures of work-family conflict predict sickness absence from work. J Occup Environ Med. 2009;51(8):879-86, http:// dx.doi.org/10.1097/JOM.0b013e3181aa5070.

34. Johns G. Attendance dynamics at work: The antecedents and correlates of presenteeism, absenteeism and productivity loss. J Occup Health Psychol. 2011;15(4):483-500, http:// dx.doi.org/10.1037/a0025153.

35. Karasek R, Brisson C, Kawakami N, Houtman I, Bongers P, Amick B. The Job Content Questionnaire (JCQ): An instrument for internationally comparative assessments of psychosocial job characteristics. J Occup Health Psychol. 1998;3:322-55, http://dx.doi.org/10.1037/1076-8998.3.4.322.

36. Siegrist J, Starke D, Chandola T, Godin I, Marmot M, Niedhammer I, et al. The measurement of effort-reward imbalance at work: European comparisons. Soc Sci Med. 2004;58:148399, http://dx.doi.org/10.1016/S0277-9536(03)00351-4.

37. Casini A, Godin I, Clays E, Kittel F. Gender difference in sickness absence from work: A multiple mediation analysis of psychosocial factors. Eur J Public Health. 2013;23(4): 635-42, http://dx.doi.org/10.1093/eurpub/cks183.

38. Quine L. Workplace bullying in NHS community trust: Staff questionnaire survey. BMJ. 1999;318:228-32, http://dx.doi. org/10.1136/bmj.318.7178.228.
39. Kelloway E, Gottlieb B, Barham L. The source, nature, and direction of work and family conflict: A longitudinal investigation. J Occup Health Psychol. 1999;4(4):337-46, http:// dx.doi.org/10.1037/1076-8998.4.4.337.

40. Niedhammer I, Sultan-Taïeb H, Chastang J, Vermeylen G, Parent-Thirion A. Exposure to psychosocial work factors in 31 European countries. Occup Med. 2012;62(3):196-202, http://dx.doi.org/10.1093/occmed/kqs020.

41. Klitzman S, House JS, Israel BA, Mero RP. Work stress, nonwork stress and health. J Behav Med. 1990;13(3):221-43, http://dx.doi.org/10.1007/BF00846832.

42. McCrae RR, Costa PT. Personality in adulthood. New York (NY): Guilford; 1990.

43. Karasek R, Theorell T. Healthy work. Stress, productivity, and the reconstruction of working life. New York: Basic Books; 1990.

44. Munir F, Yarker J, Haslam C. Sickness absence management: Encouraging attendance or "risk-taking" presenteeism in employees with chronic illness? Disabil Rehabil. 2008;30(19): 1461-72, http://dx.doi.org/10.1080/09638280701637380.

45. Vaananen A, Kumpulainen R, Kevin M, Ala-Mursula L, Kouvonen A, Kivimäki M, et al. Work-family characteristics as determinants of sickness absence: A large-scale cohort study of three occupational grades. J Occup Health Psychol. 2008;13:181-96, http://dx.doi.org/10.1037/1076-8998. 13.2.181.

46. Jansen N, Kant I, van Amelsvoort L, Kristensen T, Swaen G, Nijhuis F. Work-family conflict as a risk factor for sickness absence. Occup Environ Med. 2006;63:488-94, http://dx.doi. org/10.1136/oem.2005.024943.

47. Kristensen T. The demand-control-support model: Methodological challenges for future research. Stress Med. 1995;11:17-26, http://dx.doi.org/10.1002/smi.2460110104.

48. Lahey BB. Public health significance of neuroticism. Am Psychol. 2009;64:241-56, http://dx.doi.org/10.1037/a0015309.

This work is available in Open Access model and licensed under a Creative Commons Attribution-NonCommercial 3.0 Poland License - http://creativecommons.org/ licenses/by-nc/3.0/pl/deed.en. 